\title{
Pathogens of peritoneal dialysis peritonitis: Trends from a single-center experience over 15 years
}

\author{
Tae Yeon Hwang ${ }^{\mathbb{(}}$, Myung Gyu Kim ${ }^{\mathbb{B}}$, Se Won $\mathrm{Oh}^{(\mathbb{D}}$, Sang-Kyung Jo ${ }^{\mathbb{1}}$, Won-Yong Cho ${ }^{(\mathbb{D}}$, Jihyun Yang \\ Division of Nephrology, Department of Internal Medicine, Korea University Anam Hospital, Seoul, Republic of Korea
}

\begin{abstract}
Background: Concerns are increasing about the emergence of pathogens with antibiotic resistance in peritoneal dialysis (PD) peritonitis. We investigated the current pathogen trends and risk factors in PD peritonitis.

Methods: We conducted a retrospective study analyzing data from 643 patients who maintained PD over 3 months between January 2001 and December 2015. The isolated pathogens from PD peritonitis were compared between period A (2001-2008) and period B (2009-2015).

Results: Among 643 PD patients, 252 patients experienced one or more episodes of PD peritonitis (total 308 episodes) during the median follow-up of 66 months. In both periods, gram-positive bacteria were the dominant pathogens $(22.2 \%$ vs. $53.8 \%, P<0.01)$. Gram-negative bacteria showed an increasing tendency in period $B$, but without statistical significance $(17.0 \%$ vs. $23.7 \%, P=0.15)$. The culture-negative rate was improved from $57 \%$ in period $A$ to $18 \%$ in period $B(P<0.01)$. There was no increase in the prevalence of resistant pathogens such as methicillin-resistant Staphylococcus epidermidis (MRSE), Staphylococcus aureus (MRSA) and extended-spectrum beta-lactamase (ESBL)-producing Escherichia coli between periods A and B. Preserved residual renal function was associated with a lower risk of PD peritonitis (odds ratio, 0.53; 95\% confidence interval, $0.31-0.88 ; P=0.01$ ).

Conclusion: Over the past two decades, the pathogens of PD peritonitis have not significantly changed in Korea. Gram-positive organisms remained dominant, with S. epidermidis being the most common pathogen. Resistant bacteria such as MRSE, MRSA, ESBL-producing Gram-negative bacilli did not increase, but should be monitored.
\end{abstract}

Keywords: Mortality, Pathogen, Peritoneal dialysis, Peritonitis

\section{Introduction}

Peritoneal dialysis (PD) is one of the options for renal replacement therapy in end-stage renal disease patients.

Received March 25, 2019; Revised February 20, 2020;

Accepted March 5, 2020

Edited by Jongha Park, Ulsan University, Ulsan, Republic of Korea Correspondence: Jihyun Yang

Department of Internal Medicine, Korea University Anam Hospital, Korea University College of Medicine, 73 Goryeodae-ro, Seongbukgu, Seoul 02841, Republic of Korea. E-mail:coo-kie@hanmail.net

Copyright (C) 2020 by The Korean Society of Nephrology

(a) This is an open-access article distributed under the terms of the Creative Commons Attribution Non-Commercial License (http://creativecommons. org/licenses/by-nc-nd/4.0/), which permits unrestricted non-commercial use, distribution, and reproduction in any medium, provided the original work is properly cited.
While it has many advantages over hemodialysis (HD), there are several limitations. Infectious complications such as peritonitis are still major causes of PD technical failure $[1-5]$ which reduces patient quality of life $[2-4,6]$. It is important to explore recent trends in microbiology to select the appropriate empirical treatment for PD peritonitis. Historically, Staphylococcus epidermidis and Staphylococcus aureus have been the most common causes of PD peritonitis [7]. Methicillin-resistant organisms, however, are a growing concern. Current guidelines for the management of Gram-positive peritonitis recommend single agent, first generation cephalosporin or vancomycin [5]. However, this regimen has been challenged; some data showed that a high rate of methicillin-resistant organisms and a glycopeptide-based regimen may be the 
ideal first choice for empirical Gram-positive coverage $[8,9]$. In this context, the United States (US) Centers for Disease Control and Prevention have been investigating peritonitis outbreak cases in PD patients caused by specific pathogens or gram-negative pathogens, having asked clinicians to report cases since January 1,2019 . We investigated isolated pathogens, prevalence of resistant organisms, and risk factors of PD peritonitis in a single center longitudinally.

\section{Methods}

\section{Study population}

A total of 643 PD patients at the Korea University Anam Hospital that were treated from January 1, 2001 to December 31, 2015 were included. The observation period was divided into two parts (period A: 2001 to 2008 and period B: 2009 to 2015) because the culture method of PD effluent was changed in 2009. Three hundred eight episodes occurred in 252 patients. We analyzed the patients demographic records including age, sex, comorbidities, body mass index, residual renal function (RRF), and laboratory findings. The US Renal Data System defines loss of RRF as diuresis less than $200 \mathrm{~mL}$ per 24 hours, and we defined preserved RRF as self-reported urination of more than $200 \mathrm{~mL}$ per day regardless of diuretics [10]. This study was approved by the Korea University Institutional Review Board (approval number: ED 15124) and informed consent was waived.

\section{Diagnosis of PD peritonitis}

PD peritonitis was diagnosed using the International Society for Peritoneal Dialysis (ISPD) diagnostic criteria: 1) clinical features consistent with peritonitis such as abdominal pain and/or cloudy dialysis effluent; 2 ) a dialysis effluent white cell count $>100 / \mu \mathrm{L}$ or $>0.1 \times 10^{9} / \mathrm{L}$ (after a dwell time of at least 2 hours), with $>50 \%$ polymorphonuclear cells; and 3) a positive dialysis effluent culture. In addition, we defined a culture-negative but symptomatic peritonitis episode as a case of sterile peritonitis.

\section{Microbiology testing}

We used 8 to $10 \mathrm{~mL}$ of the PD effluent and inoculated it into blood enrichment aerobic and anaerobic bottles (BD BACTEC $^{\text {TM }}$ Plus Aerobic/F Culture Vials). Each pair of bottles was loaded into the BD BACTEC ${ }^{\mathrm{TM}} \mathrm{FX}$ (BD Diagnostics, Bellport, NY, USA) and three-dimensional blood culture systems and was incubated for five days. Growth status was continuously monitored by two automated blood culture systems. Gram staining and culturing with blood agar and chocolate agar plates at $35^{\circ} \mathrm{C}$ in a $5 \% \mathrm{CO}_{2}$ incubator were subsequently performed. The inoculated palates were reviewed on the following day, and the presence of visible colonies was noted. Identification of the grown organism was performed using the Vitek2 system (bioMérieux, Marcy-l'Étoile, France) and/or API ${ }^{\circledR}$ identification kits (bioMérieux).

\section{Statistical analysis}

We performed statistical analyses using the IBM SPSS version 22.0 software program (IBM Corp., Armonk, NY, USA). The data were presented as the means \pm standard deviation or the median (interquartile range) as appropriate. We compared baseline characteristics using the $t$ test for continuous variables and the chi-square test for categorical variables. We assessed the odds ratio (OR) for PD peritonitis using multivariable logistic regression analysis, including baseline demographics and laboratory variables. Survival analysis was performed using multivariable Cox proportional hazards model.

\section{Results}

Six hundred forty-three PD patients were followed between 2001 and 2015. The median follow-up duration was 66 months (total 3,537 patient-years). We divided the observation period into two parts at the year 2009, when the method of effluent culture was changed (period A: 2001-2008 and period B: 2009-2015). Table 1 shows the baseline characteristics at the first PD peritonitis episode. Most patients were treated with continuous ambulatory PD in period A (87.5\%), but automated PD increased from $13.2 \%$ in period A to $33.0 \%$ in period B. Preserved RRF was observed less frequently in period $\mathrm{A}$ than in period $\mathrm{B}$ $(30.3 \%$ vs. $48.0 \%, P<0.01)$. The concentration of hemoglobin was lower in period A than in period B $(8.2 \pm 1.6$ vs. $9.0 \pm 1.9 \mathrm{~g} / \mathrm{dL}, P<0.01)$. The concentration of $\mathrm{C}$-reactive protein was higher in period A than in period B (median 
Table 1. Comparisons of baseline characteristics between period $A$ and $B$

\begin{tabular}{|c|c|c|c|}
\hline Characteristic & $\begin{array}{c}\text { Period A } \\
(2001-2008)\end{array}$ & $\begin{array}{c}\text { Period B } \\
(2009-2015)\end{array}$ & $P$ value \\
\hline Total & $152(100.0)$ & $100(100.0)$ & \\
\hline Male & $66(43.4)$ & $45(45.0)$ & 0.45 \\
\hline Age (yr) & $51(35-64)$ & $59(42-79)$ & 0.08 \\
\hline PD type & & & $<0.01$ \\
\hline CAPD & $133(87.5)$ & $67(67.0)$ & \\
\hline APD & $20(13.2)$ & $33(33.0)$ & \\
\hline HTN & 126 (82.9) & $84(84.0)$ & 0.48 \\
\hline DM & $65(42.8)$ & $51(51.0)$ & 0.10 \\
\hline MI & $29(19.1)$ & $22(22.0)$ & 0.34 \\
\hline $\mathrm{CHF}$ & $22(14.5)$ & $26(26.0)$ & 0.02 \\
\hline CV history & $41(27.0)$ & $24(24.0)$ & 0.06 \\
\hline PVD & $7(4.6)$ & $10(10.0)$ & 0.08 \\
\hline CLD & $11(7.2)$ & $5(5.0)$ & 0.33 \\
\hline Preserved RRF ${ }^{\mathrm{a}}$ & $46(30.3)$ & $48(48.0)$ & $<0.01$ \\
\hline $\mathrm{Hb}(\mathrm{g} / \mathrm{dL})$ & $8.2 \pm 1.6$ & $9.0 \pm 1.9$ & $<0.01$ \\
\hline CRP (mg/L) & $3.6(0.5-26.5)$ & $2.2(0.4-41.2)$ & 0.04 \\
\hline BUN (mg/dL) & $80 \pm 38$ & $79 \pm 34$ & 0.85 \\
\hline $\mathrm{Cr}(\mathrm{mg} / \mathrm{dL})$ & $8.7 \pm 3.7$ & $8.1 \pm 4.7$ & 0.43 \\
\hline Total $\mathrm{CO}_{2}(\mathrm{mmol} / \mathrm{L})$ & $18 \pm 5$ & $18 \pm 5$ & 0.90 \\
\hline Albumin (g/dL) & $3.3 \pm 0.6$ & $3.7 \pm 1.9$ & 0.09 \\
\hline $\mathrm{BMI}\left(\mathrm{kg} / \mathrm{m}^{2}\right)$ & $24.1 \pm 3.4$ & $24.7 \pm 3.6$ & 0.17 \\
\hline $\mathrm{Ca}(\mathrm{mg} / \mathrm{dL})$ & $8.1 \pm 1.1$ & $7.9 \pm 1.1$ & 0.26 \\
\hline $\mathrm{P}(\mathrm{mg} / \mathrm{dL})$ & $5.7 \pm 1.8$ & $5.3 \pm 1.7$ & 0.15 \\
\hline Uric acid (mg/dL) & $7.6 \pm 2.3$ & $7.5 \pm 2.4$ & 0.82 \\
\hline LDL-cholesterol (mg/dL) & $95 \pm 42$ & $83 \pm 32$ & 0.12 \\
\hline Initial KT/V & $1.9 \pm 0.3$ & $2.5 \pm 1.7$ & 0.02 \\
\hline
\end{tabular}

Data are presented as number (\%), median (interquartile range), or mean \pm standard deviation.

APD, automated peritoneal dialysis; BMI, body mass index; BUN, blood urea nitrogen; CAPD, continuous ambulatory peritoneal dialysis; CHF, congestive heart failure; CLD, chronic liver disease; $\mathrm{Cr}$, creatinine; CRP, C-reactive protein; $\mathrm{CV}$, cardiovascular; DM, diabetes mellitus; Hb, hemoglobin; HTN, hypertension; LDL, low density lipoprotein; MI, myocardial infarction; PD, peritoneal dialysis; $P V D$, peripheral vascular disease; RRF, residual renal function

${ }^{a}$ Preserved RRF was defined as self-reported urination greater than $200 \mathrm{~mL}$ per day with or without diuretics.

3.6 [interquartile range, $0.5-26.5]$ vs. $2.2[0.4-41.2] \mathrm{mg} / \mathrm{L}$, $P=0.04)$.

A total of 308 PD peritonitis episodes occurred in 252 patients. Thirty-six patients experienced PD peritonitis more than once. The average peritonitis rate was significantly decreased from 1.63 episode/person-year in period A to 0.30 episode/person-year in period B $(P<$ $0.01)$. Specific pathogens were isolated in 200 cases of
Table 2. Comparisons of isolated pathogens between period A and $B$

\begin{tabular}{|c|c|c|c|c|}
\hline Pathogen & Total & $\begin{array}{c}\text { Period A } \\
(2001-2008)\end{array}$ & $\begin{array}{c}\text { Period B } \\
(2009-2015)\end{array}$ & $P$ value \\
\hline Episodes & $308(100.0)$ & 135 (100.0) & $173(100.0)$ & \\
\hline $\begin{array}{l}\text { Gram positive } \\
\text { bacteria }\end{array}$ & $123(39.9)$ & $30(22.2)$ & $93(53.8)$ & $<0.01$ \\
\hline $\begin{array}{l}\text { Staphylococcus } \\
\text { epidermidis }\end{array}$ & $36(11.7)$ & 19 (14.1) & $17(9.8)$ & \\
\hline $\begin{array}{l}\text { Staphylococcus } \\
\text { aureus }\end{array}$ & $22(7.1)$ & $8(5.9)$ & $14(8.1)$ & \\
\hline Others & 65 (21.1) & $3(2.2)$ & $62(35.8)$ & \\
\hline $\begin{array}{l}\text { Gram negative } \\
\text { bacteria }\end{array}$ & $64(20.8)$ & $23(17.0)$ & $41(23.7)$ & 0.15 \\
\hline Escherichia coli & $19(6.2)$ & $8(5.9)$ & $11(6.4)$ & \\
\hline $\begin{array}{l}\text { Klebsiella } \\
\text { pneumoniae }\end{array}$ & $9(2.9)$ & $5(3.7)$ & $4(2.3)$ & \\
\hline $\begin{array}{l}\text { Pseudomonas } \\
\text { aeruginosa }\end{array}$ & $8(2.6)$ & $3(2.2)$ & $5(2.9)$ & \\
\hline Others & $28(9.1)$ & $7(5.2)$ & 21 (12.1) & \\
\hline Polymicrobial & $6(1.9)$ & $2(1.5)$ & $4(2.3)$ & 0.60 \\
\hline Fungi & $6(1.9)$ & $2(1.5)$ & $4(2.3)$ & 0.60 \\
\hline Mycobacterium & $1(0.3)$ & $1(0.7)$ & $0(0.0)$ & 0.26 \\
\hline Culture-negative & $108(35.1)$ & 77 (57.0) & 31 (17.9) & $<0.01$ \\
\hline
\end{tabular}

Data are presented as number (\%).

308 PD peritonitis episodes for the entire period. The culture-positive rate was $64.9 \%$. Gram-positive bacteria were isolated in 123 cases, Gram-negative bacteria in 64 cases, polymicrobials in 6 cases, fungi in 6 cases and mycobacteria in 1 case (Table 2). The most common pathogens were $S$. epidermidis, S. aureus, and Escherichia coli. The culture-positive rate was significantly improved from $43.0 \%$ in period A to $82.1 \%$ in period B $(P<0.01)$. The trend of isolated organisms did not differ between period A and period B. In period A, methicillin-resistant $S$. aureus (MRSA) was isolated in 3 cases and extendedspectrum beta-lactamase (ESBL)-producing E. coli in 1 case. In period B, methicillin-resistant $S$. epidermidis (MRSE) and MRSA were noted in 2 cases, and ESBL (+) E. coli was reported in 2 cases. Drug-resistant strains did not increase over time.

Preserved RRF was associated with a lower risk of PD peritonitis in multivariable logistic analysis including sex, age at PD initiation, hypertension, diabetes, congestive heart failure, and history of cardiovascular disease (OR, 0.53; 95\% confidence interval [CI], 0.31-0.88; $P=$ 0.01 ) (Table 3). A total of 93 patients died during follow- 
Table 3. Risk factors for PD peritonitis by logistic regression analysis

\begin{tabular}{|c|c|c|c|c|c|c|}
\hline & \multicolumn{3}{|c|}{ Univariable } & \multicolumn{3}{|c|}{ Multivariable } \\
\hline & OR & $95 \% \mathrm{Cl}$ & $P$ value & OR & $95 \% \mathrm{Cl}$ & $P$ value \\
\hline Male & 1.00 & $0.72-1.38$ & 0.99 & 1.01 & $0.69-1.49$ & 0.94 \\
\hline Age (yr) (PD initiation) & 1.00 & $0.99-1.01$ & 0.43 & 1.00 & $0.99-1.01$ & 0.97 \\
\hline HTN & 2.40 & $1.65-3.49$ & $<0.01$ & 0.94 & $0.51-1.75$ & 0.85 \\
\hline $\mathrm{DM}$ & 0.87 & $0.63-1.21$ & 0.41 & 0.81 & $0.55-1.19$ & 0.27 \\
\hline $\mathrm{CHF}$ & 1.40 & $0.93-2.15$ & 0.12 & 1.18 & $0.73-1.90$ & 0.51 \\
\hline CV history & 1.63 & $0.97-2.73$ & 0.07 & 1.35 & $0.72-2.53$ & 0.28 \\
\hline Preserved RRF & 0.53 & $0.36-0.77$ & $<0.01$ & 0.53 & $0.31-0.88$ & 0.01 \\
\hline $\mathrm{BMI}\left(\mathrm{kg} / \mathrm{m}^{2}\right)$ & 1.02 & $0.97-1.08$ & 0.45 & & & \\
\hline $\mathrm{Hb}(\mathrm{g} / \mathrm{dL})$ & 0.97 & $0.87-1.08$ & 0.58 & & & \\
\hline CRP (mg/L) & 1.00 & $1.00-1.01$ & 0.83 & & & \\
\hline BUN (mg/dL) & 0.99 & $0.99-1.00$ & 0.66 & & & \\
\hline $\mathrm{Cr}(\mathrm{mg} / \mathrm{dL})$ & 0.99 & $0.96-1.03$ & 0.65 & & & \\
\hline Total $\mathrm{CO}_{2}(\mathrm{mmol} / \mathrm{L})$ & 0.98 & $0.95-1.03$ & 0.57 & & & \\
\hline Albumin (g/dL) & 1.10 & $0.91-1.33$ & 0.32 & & & \\
\hline $\mathrm{Ca}(\mathrm{mg} / \mathrm{dL})$ & 0.98 & $0.83-1.14$ & 0.75 & & & \\
\hline$P(m g / d L)$ & 0.92 & $0.82-1.02$ & 0.10 & & & \\
\hline Uric acid (mg/dL) & 0.91 & $0.84-0.98$ & 0.02 & & & \\
\hline LDL-cholesterol (mg/dL) & 1.00 & $0.99-1.01$ & 0.72 & & & \\
\hline Initial KT/V & 0.91 & $0.70-1.18$ & 0.46 & & & \\
\hline
\end{tabular}

$\mathrm{BMI}$, body mass index; BUN, blood urea nitrogen; CHF, congestive heart failure; $\mathrm{Cl}$, confidence interval; $\mathrm{Cr}$, creatinine; CRP, C-reactive protein; CV, cardiovascular; DM, diabetes mellitus; Hb, hemoglobin; HTN, hypertension; LDL, low density lipoprotein; OR, odds ratio; PD, peritoneal dialysis; RRF, residual renal function.

${ }^{a}$ Preserved RRF was defined as self-reported urination greater than $200 \mathrm{~mL}$ per day with or without diuretics.

Table 4. Risk factors for mortality in PD patients by Cox proportional hazard model

\begin{tabular}{|c|c|c|c|c|c|c|}
\hline & \multicolumn{2}{|c|}{ Model 1} & \multicolumn{2}{|c|}{ Model 2} & \multicolumn{2}{|c|}{ Model 3} \\
\hline & $\mathrm{HR}(95 \% \mathrm{Cl})$ & $P$ value & $\mathrm{HR}(95 \% \mathrm{Cl})$ & $P$ value & $\mathrm{HR}(95 \% \mathrm{Cl})$ & $P$ value \\
\hline Age (yr) (PD initiation) & 1.07 (1.06-1.09) & $<0.01$ & $1.78(1.09-2.90)$ & 0.02 & $1.01(1.00-1.01)$ & $<0.01$ \\
\hline Peritonitis episode & $1.28(0.94-1.75)$ & 0.12 & $1.25(0.92-1.71)$ & 0.15 & $1.20(0.77-1.85)$ & 0.42 \\
\hline HTN & & & $1.25(0.84-1.85)$ & 0.28 & $1.02(0.47-2.22)$ & 0.95 \\
\hline CLD & & & $1.27(0.73-2.22)$ & 0.40 & $1.97(0.99-3.85)$ & 0.05 \\
\hline PVD & & & $1.78(0.96-2.90)$ & 0.06 & $1.68(0.83-3.39)$ & 0.15 \\
\hline $\mathrm{BMI}\left(\mathrm{kg} / \mathrm{m}^{2}\right)$ & & & & & $1.04(0.98-1.10)$ & 0.18 \\
\hline RRF & & & & & $1.06(0.76-1.48)$ & 0.75 \\
\hline $\mathrm{Hb}(\mathrm{g} / \mathrm{dL})$ & & & & & $1.02(0.89-1.16)$ & 0.80 \\
\hline
\end{tabular}

$\mathrm{BMI}$, body mass index; $\mathrm{Cl}$, confidence interval; CLD, chronic liver disease; CRP, C-reactive protein; CV, cardiovascular; DM, diabetes mellitus; Hb, hemoglobin; HR, hazard ratio; HTN, hypertension; OR, odds ratio; PD, peritoneal dialysis; PVD, peripheral vascular disease; RRF, residual renal function.

Model 1, multivariate factors of age, sex, PD episode; Model 2, multivariate factors of Model 1 factors plus comorbidities (HTN, DM, CHF, CV history, CLD, PVD); Model 3, multivariate factors of Model 2 plus BMI, RRF, and laboratory test results (HB, CRP).

up. In multivariable Cox analysis, the age at PD initiation was associated with a higher mortality (hazard ratio [HR], $1.01 ; 95 \%$ CI, $1.00-1.01 ; P<0.01)$, but PD peritonitis episode was not (HR, 1.20; 95\% CI, $0.77-1.85 ; P=0.42)$

(Table 4). 


\section{Discussion}

Among the 643 patients on maintenance PD, 308 PD peritonitis episodes were identified in 256 patients. The average rate of PD peritonitis decreased over time. Grampositive organisms were dominant, in which the most common pathogen was $S$. epidermidis. The trend of isolates did not change over time. Drug-resistant strains, such as MRSE, MRSA or ESBL (+) E. coli were still rare. Preserved RRF was associated with a lower risk of PD peritonitis.

PD has several advantages compared with HD, such as home-based renal replacement therapy, cost-effectiveness and hemodynamic stability $[11,12]$. The risk of complications, however, remains an obstacle. Peritonitis and exit-site infection are common adverse events. The $\mathrm{PD}$-associated infection rates were reported as 0.24 to 1.66 episodes/patient-year $[13,14]$. This rate has gradually decreased over time from 1.37 episodes/patient-year in 1991 to 0.55 episodes/patient-year in 1998 [7]. In our study, the average rate of PD peritonitis decreased from 1.63 episode/person-year in 2001-2008 to 0.30 episode/ person-year in 2009-2015. Based on international guidelines, the last rate, below 0.50 episode/patient-year, is acceptable [5]. This improvement may result from advances in connecting systems, an increase in automated PD proportions and active patient education. Patient education can be applied to prevent and treat PD peritonitis as quickly as possible, which improves the outcomes.

In our experience, using the BACTEC ${ }^{\mathrm{TM}} \mathrm{FX}$ (BD Diagnostics, Bellport, NY, USA) culture system significantly reduced the culture-negative rate. The culture-negative rate was decreased from $57 \%$ in period A to $18 \%$ in period B. In a United Kingdom study the culture-negative rate was $19.4 \%$ in the post-millennium period (2000-2007) [15]. Improvements in the culture yield can facilitate more appropriate antibiotic selection and improve outcomes. The analysis indicated that Gram-positive organisms were dominant over time, but Gram-negative pathogens were becoming more frequent in Period B. It is important to determine recent trends of causative pathogens in PD peritonitis for empirical antibiotic therapy. Studies have reported that some pathogens are more severe, which necessitates additional caution, and requires careful consideration for catheter removal [3,6,16-19]. South Korea has been reported to use antibiotics widely, which is causing concerns about drug-resistant infection [20,21]. Antibiotic use and resistance may impact the hospital stay length, complications, mortality and medical costs [22,23]. According to the Organization for Economic Cooperation and Development (OECD) report, South Korea ranked as the third highest country in terms of antibiotic prescriptions in 2016 [23]. The growing concern about resistant organisms including MRSA, ESBL (+) Gram-negative pathogens, vancomycin-resistant enterococci (VRE), and carbapenem-resistant enterobacteriaceae (CRE), can indicate potential serious problems for PD peritonitis. Fortunately in our study, there was no increase in resistant strains despite the fact that PD patients were often hospitalized and treated with antibiotics more frequently than the general population. Our observation did not support that glycopeptide-based regimens would be superior to first-generation cephalosporin-based regimens in regard to concerns about resistant gram-positive pathogens. The current PD peritonitis guidelines recommend that the first treatment choice to cover MSSE or MSSA and gramnegative bacilli, which is a double cephalosporin-strategy, can be appropriate and effective. However, it is important to monitor and contain the pathogen status under control with local standard strategies.

Our study demonstrated that decreased RRF was a risk factor for PD peritonitis. This result could be attributable to the fact that patients with RRF need fewer dialysate changes per day and tend to be treated with automated peritoneal dialysis. South Korea is a rapidly ageing society and the age for starting renal replacement therapy has increased over time. Our observation showed that the greater the patients' age at the start of PD, the higher the mortality. However, this result should be interpreted with caution. Even after adjusting for comorbidities and other factors, the association of age with mortality is at high risk of confounding by uncaptured variables. In addition, lag time bias should be considered. Therefore, more attention should be focused on modifiable risk factors rather than age itself.

This study has several limitations. First, this study is a retrospective study in a single center. It cannot represent the whole epidemiology of Korea. Second, we might have missed some patients' information or laboratory findings, including accurate ruling out of exit-site infection only vs. combined PD peritonitis. This may result in unexpected bias. Third, we did not separate the analysis into 
patients per PD peritonitis episodes, except for when the pathogen review was conducted. Patients were aligned to the time when they first experienced the PD peritonitis episode. Fourth, mortality was collected but we could not analyze cause of death, so that impact of PD peritonitis or pathogen on mortality was beyond the scope of the study.

In conclusion, the pathogens associated with PD peritonitis have not significantly changed in the past two decades in Korea. Gram-positive organisms remained dominant, with $S$. epidermidis being the most common pathogen. Resistant strains such as MRSE, MRSA, and ESBL (+) Gram-negative bacteroides are not currently a major concern in PD peritonitis but should be monitored.

\section{Conflicts of interest}

All authors have no conflicts of interest to declare.

\section{Authors' contributions}

Tae Yeon Hwang and Jihyun Yang provided the conception, design, analysis, review and interpretation of data, drafting and revising the article final approval of the version to be published. Myung Gyu Kim, Se Won Oh, SangKyung Jo, and Won-Yong Cho provided intellectual content and statistical analysis of the data, and also provided intellectual content of critical importance to the work and technical support. All authors read and approved the final manuscript.

\section{References}

[1] Jain AK, Blake P, Cordy P, Garg AX. Global trends in rates of peritoneal dialysis. J Am Soc Nephrol 2012;23:533-544.

[2] Pérez Fontan M, Rodríguez-Carmona A, García-Naveiro R, Rosales M, Villaverde P, Valdés F. Peritonitis-related mortality in patients undergoing chronic peritoneal dialysis. Perit Dial Int 2005;25:274-284.

[3] Davenport A. Peritonitis remains the major clinical complication of peritoneal dialysis: the London, UK, peritonitis audit 2002-2003. Perit Dial Int 2009;29:297-302.

[4] Kofteridis DP, Valachis A, Perakis K, Maraki S, Daphnis E, Samonis G. Peritoneal dialysis-associated peritonitis: clinical features and predictors of outcome. Int J Infect Dis 2010; 14:e489-e493.

[5] Li PK, Szeto CC, Piraino B, et al. ISPD peritonitis recommendations: 2016 update on prevention and treatment. Perit Dial Int 2016;36:481-508.

[6] Ghali JR, Bannister KM, Brown FG, et al. Microbiology and outcomes of peritonitis in Australian peritoneal dialysis patients. Perit Dial Int 2011;31:651-662.

[7] Zelenitsky S, Barns L, Findlay I, et al. Analysis of microbiological trends in peritoneal dialysis-related peritonitis from 1991 to 1998. Am J Kidney Dis 2000;36:1009-1013.

[8] Raygada JL, Levine DP. Methicillin-resistant staphylococcus aureus: a growing risk in the hospital and in the community. Am Health Drug Benefits 2009;2:86-95.

[9] Hassoun A, Linden PK, Friedman B. Incidence, prevalence, and management of MRSA bacteremia across patient populations-a review of recent developments in MRSA management and treatment. Crit Care 2017;21:211.

[10] Moist LM, Port FK, Orzol SM, et al. Predictors of loss of residual renal function among new dialysis patients. J Am Soc Nephrol 2000;11:556-564.

[11] Li PK, Chow KM, Van de Luijtgaarden MW, et al. Changes in the worldwide epidemiology of peritoneal dialysis. Nat Rev Nephrol 2017;13:90-103.

[12] François K, Bargman JM. Evaluating the benefits of homebased peritoneal dialysis. Int J Nephrol Renovasc Dis 2014; 7:447-455.

[13] Akoh JA. Peritoneal dialysis associated infections: an update on diagnosis and management. World J Nephrol 2012; 1:106-122.

[14] Moon JJ, Kim MS, Park MY, Choi SJ, Kim JK, Hwang SD. Clinical aspects of peritonitis in peritoneal dialysis patient: a single center experience. Soonchunhyang Med Sci 2013; 19:72-79.

[15] Brown MC, Simpson K, Kerssens JJ, Mactier RA; Scottish Renal Registry. Peritoneal dialysis-associated peritonitis rates and outcomes in a national cohort are not improving in the post-millennium (2000-2007). Perit Dial Int 2011;31: 639-650.

[16] Salzer WL. Peritoneal dialysis-related peritonitis: challenges and solutions. Int J Nephrol Renovasc Dis 2018;11:173186.

[17] Barraclough K, Hawley CM, McDonald SP, et al. Polymicrobial peritonitis in peritoneal dialysis patients in Australia: predictors, treatment, and outcomes. Am J Kidney Dis 2010;55:121-131.

[18] Szeto CC, Kwan BC, Chow KM, et al. Repeat peritonitis in 
peritoneal dialysis: retrospective review of 181 consecutive cases. Clin J Am Soc Nephrol 2011;6:827-833.

[19] Szeto CC, Chow KM, Wong TY, Leung CB, Li PK. Conservative management of polymicrobial peritonitis complicating peritoneal dialysis--a series of 140 consecutive cases. Am J Med 2002;113:728-733.

[20] Ryu S. The new Korean action plan for containment of antimicrobial resistance. J Glob Antimicrob Resist 2017;8:7073.
[21] Livermore DM. Current epidemiology and growing resistance of gram-negative pathogens. Korean J Intern Med 2012;27:128-142.

[22] Hawkey PM. The growing burden of antimicrobial resistance. J Antimicrob Chemother 2008;62 Suppl 1:i1-i9.

[23] Rushton J, Pinto Ferreira J, Stärk KD. Antimicrobial resistance: the use of antimicrobials in the livestock sector. OECD Food Agric Fish Pap 2014;68:1-37. 